\title{
Visual Acuity in Acute Optic Neuritis Studied with Contrast Enhanced MRI
}

\author{
Duleep Bhonsale', Kapil Das², Ibtesham Khan ${ }^{3}$ \\ ${ }^{1}$ Additional Professor, Department of Radiology, \\ ${ }^{2}$ Associate Professor, ${ }^{3}$ Registrar, Department of Ophthalmology, \\ Hinduhridaysamrat Balasaheb Thackeray Medical College \& Dr RN Cooper Hospital, Juhu, Mumbai, Maharashtra, India.
}

\begin{abstract}
Background: The location and extent of an abnormal signal on MRI of an optic neuritis affected nerve has a correlation with the severity of initial visual loss and its subsequent recovery.

Objective: Contrast enhanced MRI study was done to show abnormal enhancement of the optic nerve in acute optic neuritis, to know if the abnormal enhancement correlates with presenting visual defect and its subsequent recovery. We also intended to determine the sensitivity of this modality in acute optic neuritis.

Materials and Methods: Retrospective comparative study was performed on the records and MRIs of patients who had acute optic neuritis with clinical evaluation and MRI performed within 15 days of the visual loss who were referred to our hospital during the time period of August 2015 to May 2016.Of the 59 patients who met all the study entry criteria, 51 patients had a follow up of atleast 6 months. There was no follow up of 8 patients. The data was analysed with the intention of exploring the relationship of baseline and outcome of visual acuity, colour vision, perimetry in the affected eye with the location and length of abnormal enhancement of the corresponding optic nerve
\end{abstract}

Results: The length of the abnormal enhancement did not

\section{INTRODUCTION}

MRI imaging is the most advanced scanning technique for demonstrating demyelinating lesions. ${ }^{1}$ Acute optic neuritis is a clinically symptomatic inflammatory disease of the optic nerve that is analogous to multiple sclerosis associated active inflammatory white matter lesions elsewhere in the Brain. Optic neuritis causes areas of inflammation and edema of the optic nerve which may cause a transient disruption of the blood brain barrier ${ }^{2}$ which should permit leakage of contrast material and thus enhancement on MRI images. In this study we investigated the sensitivity of Gadolinium enhanced MRI in delineating the affected segment of optic nerve. Other authors have suggested that the length and location of abnormal enhancement of optic nerve affected by optic neuritis on MRI are associated with the degree of visual loss and might predict visual outcome. , $^{3,45}$

In most cases if clinical criteria are strictly applied (Optic Neuritis Study Group, 1991) MRI is not required to diagnose optic neuritis however patients with non-arteritic AION or acute compressive neuropathy (tumor/aneurysm) or posterior scleritis may be difficult to distinguish from optic neuritis. In such cases MRI will prevent misdiagnosis. We tried to determine whether the length or location of abnormal enhancement of optic nerve could be related to the correlate to the duration of visual loss prior to MRI. For all parameters of vision, recovery was similar regardless of location or length of abnormal enhancement. Although lesions involving the optic canal or longer segment of the optic nerve have a worse initial vision, the location and length of enhancement are not predictive of recovery.

Keywords: Acute optic neuritis, Gadolinium enhanced fat suppressed MRI, Abnormal enhancement of optic nerve.

\section{${ }^{*}$ Correspondence to:}

Dr Kapil Das,

Associate Professor, Department of Ophthalmology, Hinduhridaysamrat Balasaheb Thackeray Medical College \& Dr RN Cooper Hospital, Juhu, Mumbai, Maharashtra, India.

\section{Article History:}

Received: 08-06-2016, Revised: 22-06-2016, Accepted: 18-07-2016

\begin{tabular}{|l|c|}
\hline \multicolumn{2}{|c|}{ Access this article online } \\
\hline $\begin{array}{l}\text { Website: } \\
\text { www.ijmrp.com }\end{array}$ & Quick Response code \\
\hline DOI: & \\
10.21276/ijmrp.2016.2.4.028 & \\
\hline
\end{tabular}

baseline visual loss, rate of recovery and degree of visual recovery.

\section{PATIENTS AND METHODS}

Retrospective study was performed on the records and MRIs of patients who had acute optic neuritis with clinical evaluation and MRI performed within 15 days of the visual loss who were referred to our hospital during the time period of August 2015 to May 2016. Of the 59 patients who met all the study entry criteria, 51 patients had a follow up of atleast 6 months. There was no follow up of 8 patients.

Patients were excluded if:

a) Corticosteroid was started prior to the clinical or MRI evaluation

b) The affected eye had a prior optic neuritis and the vision did not return back to $6 / 6$, mean deviation $(\mathrm{MD})<-2.0 \mathrm{~dB}$ and normal color vision (CV) by pseudoisochromatic plate testing

c) Any eye had optic disc pallor for any cause

d) There was a known Best corrected visual acuity $<6 / 12$

e) There was a visual field loss due to any ophthalmic disorder. No patients had known SLE, Sarcoidosis, Syphillis, Optic neuropathy or other known causes of optic neuropathy. 


\section{Examination}

Vision analysis was done by:

a) Best corrected snellen acuity with exam room lights off and recorded as decimal equivalent including finger counting $=0.01$, hand motion $=0.005$, light perception $=0.001$, no light perception $=0$.

b) Threshold perimetry using the 24-2 program of Humphrey perimeter, the Mean Deviation recording in decibels was used. In eyes with severe visual loss, that even a spot size III could not be used, the MD was recorded as $-35.0 \mathrm{~dB}$.

c) Colour vision was evaluated using Ishihara plates with exam room lights on.The colour vision was expressed as a decimal equivalent of the number of correct responses over the total number of test plates.

The examinations were repeated 1 (3-5 weeks), 3(10-14 weeks) and 6(5-7weeks) months.

\section{MRI Examination}

MRI examination was performed with 1.5T MRI. The examination consisted of axial T2 weighed and axial fluid attenuated inversion recovery images of the entire brain $(5 \mathrm{~mm}$ thick slices, $2 \mathrm{~mm}$ spacing) and coronal T1 and T2 weighed images from the pons to the mid globe $(4 \mathrm{~mm}$ thick slices, $0.4 \mathrm{~mm}$ spacing). After IV injection of Gadolinium, axial and coronal view of the enhanced T1 -weighed images with fat suppression ${ }^{6}$ images (3mm thick, $0.3 \mathrm{~mm}$ spacing $)^{7}$ through the pre-chiasmal optic pathways were produced. A radiologist who had no prior knowledge of the diagnosis reviewed each MRI.

Treatment

Patients were treated with IV Methyl Prednisolone, $1 \mathrm{~g}$ daily in one Or two divided doses for 3 days, followed by conventional daily dose $(60 \mathrm{mg})$ oral prednisolone for 11 days. Of the 51 patients with follow-up, 47 received treatment, 4 did not receive any steroids due to medical contraindications.

\section{RESULTS}

Of the 59 patients who met the inclusion criteria, 39 were women and 20 were men, with a mean age of 33 .There were 51 patients with adequate follow up, who were treated with steroids after MRI with 4 receiving no treatment. Optic nerve with enhancement of the optic canal had poorer color vision $(p=0.03)$ and the nerves with all segments involved had worse threshold perimetry and color vision $(p=0.007)$. Nerves with enhancement $>10 \mathrm{~mm}$ had worse threshold perimetry $(p=0.005)$, while nerves with enhancing segment $>17 \mathrm{~mm}$ had poorer baseline visual acuity $(p=0.02)$, threshold perimetry $(p=0.009)$ and color vision $(0.03)$.

Abnormal contrast enhancement of the optic nerve in acute optic neuritis is an important finding because of its high sensitivity $(97 \%)$. Furthermore, optic nerve enhancement is absent in previously affected or unaffected optic nerves and the length of the optic nerve did not correlate with the duration of visual loss prior to MRI.

\section{Data Analysis}

The analysis of the data was done to determine the relationship of the baseline and outcome visual acuity, color vision and mean deviation in the affected eye with the corresponding optic nerves location and length of abnormal enhancement. VA $<0.10, M D<$ $20.0 \mathrm{~dB}$ or $\mathrm{CV}<0.10$ determined severe visual loss. Major or good recovery was determined when $V A$ was $>=0.80$, MD was $>=3.0 \mathrm{~dB}$ or $C V$ was $>=0$.

\begin{tabular}{lccc}
\hline Location of optic nerve enhancement & All patients (n) & All patients (\%) & Patients with follow up (n) \\
\hline No enhancement & 3 & 5.08 & 3 \\
Orbit only & 27 & 45.7 & 24 \\
Canal only & 6 & 10.16 & 6 \\
Intracranial only & 3 & 5.08 & 3 \\
Orbit and canal only & 14 & 23.72 & 11 \\
Canal and intracranial only & 3 & 5.08 & 2 \\
All three segments & 3 & 5.08 & 2 \\
\hline
\end{tabular}

Persistent severe vision loss

\begin{tabular}{lccc}
\hline Category subgroup & $\begin{array}{c}\text { One month vision } \\
\text { Visual acuity }<=\mathbf{0 . 1}(\%)\end{array}$ & $\begin{array}{c}\text { Mean deviation } \\
<=\mathbf{2 0 . 0}(\%)\end{array}$ & $\begin{array}{c}\text { Colour vision } \\
<=\mathbf{0 . 1}(\%)\end{array}$ \\
\hline All patients & 5 & 3 & 7 \\
Optic nerve enhancement & 5 & 4 & 8 \\
No enhancement & 8 & 0 & 0 \\
Canal enhancement & 9 & 5 & 10 \\
No canal enhancement & 4 & 4 & 5 \\
Enhancement $>10 \mathrm{~mm}$ & 12 & 5 & 8 \\
Enhancement $<=10 \mathrm{~mm}$ & 4 & 3 & 6 \\
Enhancement $>17 \mathrm{~mm}$ & 5 & 6 & 6 \\
Enhancement $<=17 \mathrm{~mm}$ & 5 & 4 & 8 \\
All three segments enhanced & 21 & 13 & 17 \\
Not all three segments enhanced & 3 & 4 & 6 \\
\hline
\end{tabular}

No $p$ values were significant 
Baseline vision in relation to optic nerve enhancement

\begin{tabular}{|c|c|c|c|c|c|c|c|}
\hline \multirow{2}{*}{$\begin{array}{l}\text { Category subgroup } \\
\text { All patients }\end{array}$} & \multirow{2}{*}{$\begin{array}{c}\begin{array}{c}\text { No. of } \\
\text { nerves }\end{array} \\
59\end{array}$} & \multicolumn{2}{|c|}{ Visual acuity } & \multicolumn{2}{|c|}{ Mean Deviation } & \multicolumn{2}{|c|}{ Color Vision } \\
\hline & & 0.33 & 0.35 & -21.7 & 12.7 & 0.35 & 0.43 \\
\hline Optic nerve enhancement & 56 & 0.31 & 0.34 & -19.5 & 13.7 & 0.36 & 0.42 \\
\hline No enhancement & 3 & 0.17 & 0.26 & -14.8 & 13.6 & 0.32 & 0.48 \\
\hline Canal enhancement & 23 & 0.27 & 0.34 & -23.4 & 14.1 & 0.23 & 0.32 \\
\hline No canal enhancement & 36 & 0.35 & 0.36 & -20.1 & 11.6 & 0.45 & $\begin{array}{c}0.45 \\
p=0.03\end{array}$ \\
\hline Intracranial enhancement & 12 & 0.28 & 0.33 & -23.4 & 12.2 & 0.35 & 0.41 \\
\hline No intracranial enhancement & 47 & 0.31 & 0.0 .37 & -18.2 & 14.0 & 0.28 & 0.40 \\
\hline Orbital enhancement & 36 & 0.32 & 0.36 & -16.4 & 16.2 & 0.34 & 0.45 \\
\hline No orbital enhancement & 23 & 0.31 & 0.33 & -24.5 & 11.2 & 0.31 & 0.37 \\
\hline Enhancement >10mm & 32 & 0.28 & 0.32 & -20.5 & 13.1 & 0.35 & 0.41 \\
\hline Enhancement $<=10 \mathrm{~mm}$ & 27 & 0.34 & 0.36 & -17.5 & $\begin{array}{c}13.7 \\
p=0.005\end{array}$ & 0.44 & 0.46 \\
\hline Enhancement $>17 \mathrm{~mm}$ & 18 & 0.21 & 0.30 & -26.3 & 10.4 & 0.21 & 0.34 \\
\hline Enhancement $<17 \mathrm{~mm}$ & 41 & 0.36 & $\begin{array}{c}0.36 \\
p=0.02\end{array}$ & -19.2 & $\begin{array}{c}13.6 \\
p=0.009\end{array}$ & 0.42 & $\begin{array}{c}0.42 \\
p=0.03\end{array}$ \\
\hline $\begin{array}{l}\text { Orbital and canal } \\
\text { enhancement }\end{array}$ & 11 & 0.26 & 0.30 & -22.6 & 12.6 & 0.24 & 0.31 \\
\hline $\begin{array}{l}\text { No orbital and canal } \\
\text { enhancement }\end{array}$ & 48 & 0.32 & 0.34 & -18.6 & 14.1 & 0.35 & 0.41 \\
\hline $\begin{array}{l}\text { Canal and intracranial } \\
\text { enhancement }\end{array}$ & 4 & 0.37 & 0.40 & -22.4 & 13.6 & 0.45 & 0.45 \\
\hline $\begin{array}{l}\text { No canal and intracranial } \\
\text { enhancement }\end{array}$ & 55 & 0.32 & 0.35 & -21.6 & 12.7 & 0.32 & 0.41 \\
\hline All three segments enhanced & 4 & 0.18 & 0.28 & -30.3 & 7.2 & 0.07 & 0.18 \\
\hline $\begin{array}{l}\text { Not all three segements } \\
\text { enhanced }\end{array}$ & 55 & 0.31 & 0.34 & -18.2 & 14.0 & 0.38 & $\begin{array}{c}0.41 \\
p=0.007\end{array}$ \\
\hline
\end{tabular}

\section{DISCUSSION}

The normal optic nerve surrounded by the optic nerve sheath enhances mildly due to the pial vascular network. On the T1 weighted MRI, abnormal enhancement of the optic nerve affected by acute optic neuritis indicates a blood optic nerve barrier breakdown. There were no false positive MRI results. Even eyes with old optic neuritis resulting in secondary optic atrophy did not show abnormal enhancement on contrast MRI.

The T2 weighted images with fat suppression and STIR MRI without contrast demonstrate an abnormally high signal as a result of optic nerve tissue oedema, inflammation and demyelination with a loss of hydrophobic myelin in acute cases (Stewart et al., 1991), ${ }^{8}$ and perhaps axonal loss, extracellular water and gliosis (Barnes et al.,1991) ${ }^{9}$ on studies performed on chronic plaques. Fat supressed gadolinum enhanced MRI appears to be more useful for detecting acute optic neuritis than STIR because STIR can also be abnormal in previously affected optic nerves (Miller, 1988) ${ }^{10}$. Also, STIR has a lower sensitivity since only 77 (Dunker and Wiegand, 1996) to 81 (Miller et al.,1988) ${ }^{10}$ to $89 \%$ (Kapoor et al.,1998) $)^{5}$ of optic nerves affected within 30 days have demonstrable lesions. The MRI method used in our study will be beneficial in separating patients with optic neuritis and disc swelling from non-arteritic AION with some pain in the affected eye (Swartz et al., 1995). ${ }^{11}$

The mean length of the optic nerve that enhanced was $13.5 \mathrm{~mm}$, which is nearby the $10 \mathrm{~mm}$ reported by Miller et al (1988) 10 and 17.5mm reported by Dunker Weigand $(1996)^{4}$ using STIR. STIR signal more or equal to $17 \mathrm{~mm}$ usually occurred in patients with a longer duration between the onset of visual loss and performing the MRI (Kapoor et al., 1998). ${ }^{5}$ But in our case patients with gadolinium enhancement more than $17 \mathrm{~mm}$ had duration of visual loss prior to the MRI which was similar to the patients with shorter affected segments. The length of abnormal enhancement did not correlate with the number of days of visual symptoms prior to the MRI.

Only patietns with involvement of the canalicular optic nerve had worse vision, which was significant in only one modality, color vision. There were no major correlations with the $\mathrm{VA}, \mathrm{MD}, \mathrm{CV}$ and a specific abnormal segment of optic nerve.

Eyes with more than $10 \mathrm{~mm}$ of optic nerve enhancement had worse visual fields but not worse VA or CV. All three measures of vision were significantly worse for eyes with enhancement of optic nerve $>17 \mathrm{~mm}$.

By 1 month, the steroid-treated patients, who had worse baseline vision, improved the visual performance so that by 1 month the previous difference between the steroid-treated and the untreated group was no longer present.

Prior studies have shown that corticosteroids donot affect the visual outcome except to speed recovery (Beck et al. ${ }^{12}, 1992$ : Keltner et al. $\left.{ }^{13}, 1994\right)$ even with patients of STIR demonstrated lesions of the canalicular optic nerve.(Kapoor et al.,1998). ${ }^{5}$ Similar to previous studies (Beck et al 1992, 1994), 12,14 the visual 
performance improved in all groups by 1 month regardless of steroid use. This is contrasted with reports that suggest that abnormal signal length, $>15$ or $17.5 \mathrm{~mm}$, and intracanalicular location of an optic nerve lesion on MRI are associated with poor or slow recovery from optic neuritis even if treated with steroids (Miller et al. ${ }^{10}, 1988$; Dunker weigand $\left.{ }^{4}, 1996\right)$.

Recovery of visual acuity, color vision and visual field was similar for patients in our study irrespective of the presence of optic nerve enhancement. This study confirms the advantage of contrast enhanced MRI of the orbit following the diagnosis of acute optic neuritis. However it is not diagnostic of demyelinating optic neuritis because even conditions like neoplastic infiltration, SLE, rhematoid arthritis associated optic neuropathy, radiation vasculopathy, CMV posterior scleritis also cause similar clinical features. Although longer segments of optic nerve enhancement and canalicular involvement in a lesser proportion are associated with poor presenting vision; contrast enhanced MRI had no predictive value for visual outcome.

\section{ACKNOWLEDGEMENT}

Biostatistics was done by Dr. Ibtesham Khan

\section{REFERENCES}

1. Willoghby EW, Grochowski E, Li DKB, Oger J, Kastrukotf LF, Paty DW. Serial magnetic resonance scanning in multiple sclerosis: a second prospective study in relapsing patients. Ann Neurol 1989; 25:43-49.

2. Grossman Rl, Gonzalez-Scarano F, Atlas SW, Galetta S, Silberberg DH. Multiple sclerosis: gadolinium enhancement in MR imaging. Radiology 1986; $161: 721-725$.

3. Miller DH, Newton MR, van der Peel JC, et al. Magnetic resonance imaging of the optic nerve in optic neuritis. Neurology 1988; 38: 175 179

4. Dunker S, Wiegand W. Prognostic value of magnetic resonance imaging in monosymptomatic optic neuritis. Ophthalmology 1996; 103: 1768-73.

5. Kapoor R, Miller DH. Jones SJ, Plant GT, Brusa A, Gass A, et al. Effects of intravenous methyprednisolone on outcome in MRI based prognostic subgroups in acute optic neuritis. Neurology 1998; 50: 230-7.

6. Hendrix LE, Kneeland JB, Haughton, VM, Daneils DL, Szumowski $J$, Williams AL, et al. MR imaging of optic nerve lesions: value of gado pentetate demeglumine and fat-suppression technique. AJNR Am J Neuroradiol 1990; 11: 749-54.

7. Lee DH, Simon JH, Szumowski J, Feasby TE, Karlik SJ, Fox AJ, Pelz DM. Optic neuritis and orbital lesions: lipid-suppressed chemical shift MR imaging. Radiology 1991; 179: 543-6.

8. Stewart WA, Alvord, Ecr, Hruby S, Hall LD, Paty DW. Magnectic resonance imaging of experimental allergic encephalomyelitis in primates. Brain 1991; 114: 1069-96.

9. Barnes D, Munro PM, Youl BD, Prineas JW, McDonald WI. The longstanding MS lesion. A quantitative MRI and electron microscope study. Brain 1991;114: 1271-80.

10. Miller DH, Newton MR, van der Poel JC, du Boulay EP, Halliday $A M$, Kendall BE, et al. Magnetic resonance imaging of optic nerve in optic neuritis. Neurology 1988; 38: 175-9.

11. Swartz NG, Beck RW, Savino PJ, Sergott RC, Bosley TM, Lam $\mathrm{BL}$, et al. Pain in anterior ischemic optic neuropathy. J Neuroophthalmol 1995; 15: 9-10.

12. Beck RW, Cleary PA, Anderson MM, Keltner JL, Schults WT, Kaufman DI, et al. A randomized control trial of corticosteroids in the treatment of acute optic neuritis. The Optic Neuritis Study Group. N Engl J Med 1992; 326: 581-8.

13. Keltner JL, Johnson CA, Spurr JO, Beck RW, Visual field profile of optic neuritis. One year followup in the Optic Neuritis Treatment Trial. Arch Ophthalmol 1994; 112:946-53.

14. Beck RW, Cleary PA, Trobe JD, Kaufman DI, Kupersmith MJ, Paty DW,et al. the effect of corticosteroids for acute optic neuritis on the subsequent devolopment of multiple sclerosis. The Optic Neuritis Study Group. N Engl J Med 1993; 329:1764-9.

\section{Source of Support: Nil. Conflict of Interest: None Declared.}

Copyright: (c) the author(s) and publisher. IJMRP is an official publication of Ibn Sina Academy of Medieval Medicine \& Sciences, registered in 2001 under Indian Trusts Act, 1882.

This is an open access article distributed under the terms of the Creative Commons Attribution Non-commercial License, which permits unrestricted non-commercial use, distribution, and reproduction in any medium, provided the original work is properly cited.

Cite this article as: Duleep Bhonsale, Kapil Das, Ibtesham Khan. Visual Acuity in Acute Optic Neuritis Studied with Contrast Enhanced MRI. Int J Med Res Prof. 2016; 2(4):117-20. 